\title{
Rupture of Accura balloon during percutaneous transvenous mitral commissurotomy
}

\author{
Pradhan $\mathrm{S}^{* 1}$, Sahoo $\mathrm{PK}^{1}$, Mallick $\mathrm{S}^{2}$, Padhi $\mathrm{JK}^{1}$ \\ ${ }^{1}$ Apollo Hospitals, Bhubaneswar, Odisha, India \\ ${ }^{2}$ SCB Medical College, Cuttack, Odisha, India
}

Received: April 24, 2016

DOI: $10.5430 /$ crim.v4n1p1
Accepted: August 14, 2016

Online Published: October 23, 2016

\begin{abstract}
Percutaneous transvenous mitral commissurotomy (PTMC) is one of the treatment modality in the management of rheumatic mitral stenosis. Reuse of sterilized PTMC balloon catheters has been widely practiced in developing countries to bring down procedural cost. PTMC by reused balloons are prone to deform and rupture during procedure. This can cause fatal complications like embolism of air or balloon material. Herein, we report a case of Accura balloon rupture during PTMC without any fatal complication. Thus, during balloon preparation particularly of reused balloon, it should be examined for any deformity or tear and air should be removed completely to prevent the fatal outcome.
\end{abstract}

Key Words: Rheumatic heart disease, Mitral stenosis, Percutaneuos transvenous mitral commissurotomy, Accura balloon rupture

\section{INTRODUCTION}

Rheumatic Heart Disease remains a major health concern and associated with increasing morbidity \& mortality in developing countries, like India. PTMC using the Accura (Vascular Concepts Limited, China) or Inoue (Toray, Tokyo, Japan) balloon catheter is now an established mode of therapy for suitable cases of mitral stenosis with a success rate of more than $90 \%$. Morbidity and mortality is less in PTMC than surgical procedure, hence it became more liberal mode of treatment in mitral stenosis. PTMC by Inoue balloon is the most commonly used but Accura balloon is as effective and cheaper alternative to Inoue balloon. Reuse of sterilized balloon is widely practiced in India to bring down the cost of procedure. The safety of the resterilized hardware for PTMC has been reported. ${ }^{[1]}$ PTMC by reused balloons are prone to deform and rupture during procedure. The rupture of balloon during PTMC is a rare complication \& very few cases have been reported. Herein, we report a case of Accura balloon rupture during PTMC due to tear in the proximal part of balloon.

\section{CASE REPORT}

A 28-year-old female presented with dyspnea of NYHA functional class II for one year and having exacerbation of symptom that is dyspnea NYHA class III since last 2 weeks. On examination, there was regular pulse and raised jugular venous pressure with prominent A wave. Cardiac auscultation revealed long mid-diastolic murmur with presystolic accentuation. Routine blood investigations were within normal limits. Transthoracic echocardiography confirmed severe rheumatic MS of mitral valve orifice area of $0.9 \mathrm{~cm}^{2}$, mean transmitral gradient of $25 \mathrm{mmHg}$ with peak pulmonary arte-

\footnotetext{
*Correspondence: Pradhan S; Email: susantapradhan77@gmail.com; Address: Apollo Hospitals, Sainik School Road, Unit-15 Bhubaneswar, Odisha, India.
} 
rial pressure of $64 \mathrm{mmHg}$ and trivial MR. Trans-esophageal echocardiography revealed no clot in left atrium or left atrial appendages. After informed written consent, the patient was taken for PTMC. Hemodynamic data of the patient: pulmonary artery pressure $117 / 40 \mathrm{mmHg}$ and mean $78 \mathrm{mmHg}$, pulmonary capillary wedge pressure $25 \mathrm{mmHg}$ and left ventricular end diastolic pressure $13 \mathrm{mmHg}$. Patient developed cardiac tamponade during manipulation of Brockenbrough needle before trans-septal puncture. Patient was immediately intubated, pigtail catheter was introduced in the pericardial space and pericardiocentesis was done. The procedure was abandoned and cardiothoracic surgeon opinion was taken. Patient's relatives were not willing for a surgical procedure. As there was no further accumulation of pericardial fluid, next day patient was taken for PTMC once again after obtaining high risk consent. After successful trans-septal puncture using Brockenbrough needle-Mullin sheath assembly, 0.025 inch coiled guide wire was inserted into the left atrium. A prechecked, $26 \mathrm{~mm}$ Accura balloon (Vascular Concepts Limited, China) catheter was inserted over the wire in the left atrium and was crossed across the mitral valve using a J-shaped stylet. The balloon was inflated with the 1:4 diluted contrast-saline mixtures up to $26 \mathrm{~mm}$ keeping at MV orifice. The distal part of the balloon inflated first followed by the proximal part. Than during inflation, the proximal part of balloon suddenly ruptured and collapsed (see Figure 1).

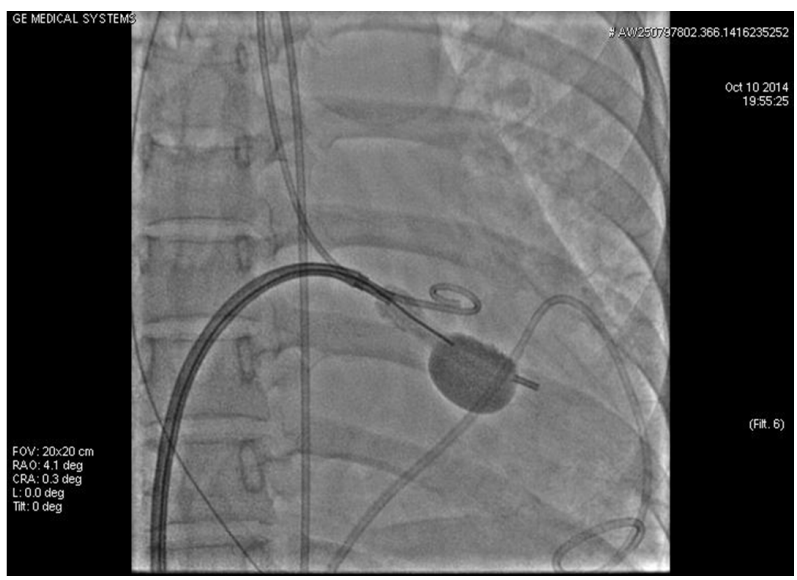

Figure 1. Angiographic appearance of collapsed proximal segment after rupture of Accura balloon catheter

After inserting the coiled guide wire in left atrium, the ruptured balloon was removed. A rupture of the proximal part of the balloon was seen (see Figure 2).

Post PTMC Mitral valve area was $2.1 \mathrm{~cm}^{2}$, but unfortunately patient developed moderate mitral regurgitation. Patient became asymptomatic with medical management. Patient was explained regarding possible need for mitral valve replace- ment in near future if response to medically therapy inadequate. Patient was discharged safely and advised for follow up. In our case the rupture might be due to poor quality or fatigue of nylon-mesh layer of reused balloon.

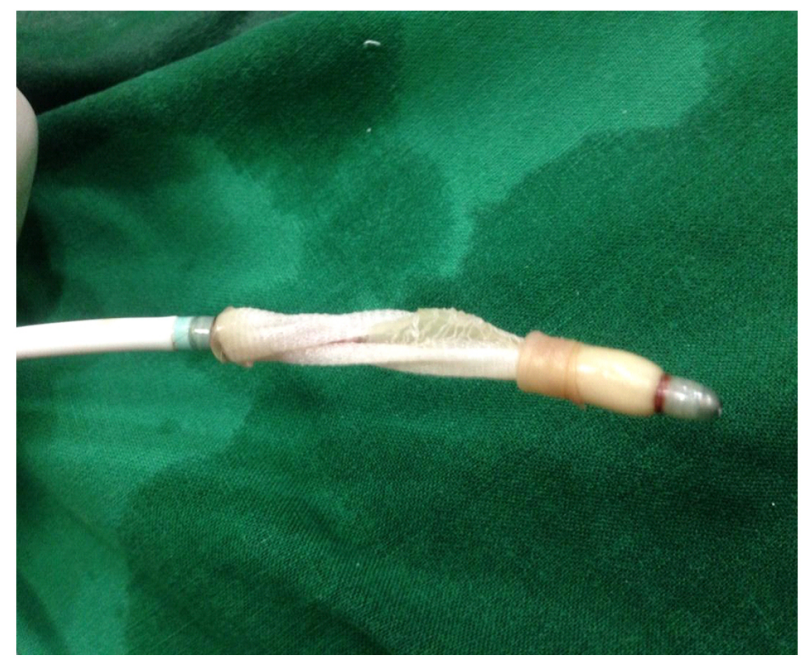

Figure 2. Ruptured proximal segment of Accura balloon

\section{Discussion}

Inoue et al., introduced their balloon catheter for PTMC in 1984. ${ }^{[2]}$ Since then it has been remained the first line of treatment for selected patients of rheumatic MS. PTMC has shown excellent efficacy \& safety, but the cost of catheter is a limitation. Accura balloon has been used as the preference of choice in developing countries like India due to lower cost and similar proven efficacy. ${ }^{[3]}$ Both the Accura and Inoue balloon are made from Poly vinyl chloride with a balloon attached to the distal end. Both the balloons are composed of 3 layers. There is an outer latex layer, intermediate mesh layer and inner latex layer. The nylon mesh is winding with thin rubber band and it is winding more tightly in the central region than both ends. The nylon mesh regulates maximum diameter and inner pressure of the balloon. The distal segment of the balloon is more compliant so it inflates first, followed by proximal $\&$ finally the middle segment. Unlike the Accura balloon, the Inoue balloon has an additional vent in the balloon lumen and two small holes on the outer latex layer. The blood can enter the space between latex layers and can get embedded within the mesh layer, which is difficult to be cleaned during resterilisation. This may be one of the factor contributing to the rupture of the Inoue balloon. The Accura balloon is more compliant \& volume driven. It is known that Accura balloon can deliver more stable and higher pressure when the balloon is inflated within the stated diameter range. ${ }^{[4]}$ The studies has shown that Accura balloons can be reused safely and effectively to reduce the cost of the procedure. Balloon rupture is a rare 
occurrence during PTMC. This happens more frequently in the developing countries, where balloon catheters are re-used. Balloon rupture during interventional procedures could occur owing to accidental or intentional use of high inflation pressures, abrasive effect of calcified mitral valve, avulsing effect to balloon while squeezing through narrowed orifice or it can be due to quality or fatigue of the nylon-rubber mesh layer. A deformity of the Inoue balloon catheter was noted in $1.6 \%$ and actual rupture of deformed balloon occurred in $0.4 \%$ in a series reported by Ho et al. ${ }^{[5]}$ All deformities were found at the distal portion of balloon and none of the patient developed any complication. Chow et al. reported two cases of proximal balloon tear during PTMC by Inoue balloon and they attributed to the suboptimal quality of rubber layer might be responsible. ${ }^{[6]}$ Schilling et al. reported two cases of balloon tear occurring in the proximal portion of the Inoue balloon. ${ }^{[7]}$ They reported that the rupture was associated with calcify valves. Singla et al. reported a case of Accura balloon rupture in distal part during PTMC and no complication had occurred. ${ }^{[8]}$ In our case the Accura balloon ruptured in proximal part. To the best of our knowledge rupture of Accura balloon is being reported for second time and our case is the first observed case of Accura balloon rupture in proximal segment. The rupture of the balloon may get complicated with air embolism, embolisation of torn latex and cardiac perforation. Fortunately, no complication was seen in our case. It is therefore important to be aware of the Accura balloon rupture during PTMC, especially when reused. To prevent this some precautions should be followed. During preparation, the balloon should be checked for abnormal shape or tear. Meticulous care should be taken for complete removal of air from the balloon. There should not exceed the maximum recommended inflation volume marked in the syringe provided with the balloon catheter. Dilute contrast medium should be injected slowly to inflate the balloon during test inflations in order to avoid rapid stretching of the mesh layer.

\section{CONFLICTS OF INTEREST DISClOSURE}

The authors have declared no conflicts of interest.

\section{REFERENCES}

[1] Nair KK, Pillai, Thajudeen A, et al. Comparative study on safety, efficacy and midterm results of balloon mitral valvotomy performed with triple luman and double lumen mitral valvotomy catheters. Cathet Cardiovasc Interv. 2012; 80: 978-86. PMid:22566347 http: $/ /$ dx.doi.org/10.1002/ccd.24284

[2] Inoue K, Owaki T, Nakamura T, et al. Clinical application of transvenous mitral commissurotomy by a new balloon catheter. J Thorac Cardiovasc Surg. 1984; 87: 394-402. PMid:6700245

[3] Nanjappa MC, Dorros G, Hemann SK, et al. The Indian experience of percutaneous transvenous mitral commissurotomy: comparison of the triple lumen and double lumen variable sized single balloon with regard to procedural outcome and cost savings. J Interv Cardiol. 1998; 11: 107-112. http://dx.doi.org/10.1111/j.1540-818 3.1998.tb00105.x
[4] Harikrishnan S ed. Percutaneous mitral valvotomy. New Delhi: Jaypee Brothers Medical Publishers(P) Ltd. 2012.

[5] Ho YL, Chen WJ, Wu CC, et al. Inoue balloon deformity and rupture during percutaneous balloon valvulaplasty. Cathet Cardiovasc Diagn. 1996; 38: 345-50. http://dx.doi.org/10.1002/(SICI ) 1097-0304 (199608) 38:4<345: :AID-CCD3>3.0.CD;2-7

[6] Chow WH, Chow TC, Cheung KL. Angiographic recognition of a proximal balloon tear during Inoue balloon mitral valvotomy. Cathet and Cardiovasc Diagn. 1993; 28: 235-237. http://dx.doi.org/1 $0.1002 / \mathrm{ccd} .1810280310$

[7] Schilling RJ, Francis CM, Shaw TRD, et al. Inoue balloon rupture during dilatation of calcified mitral valves. Br Heart J. 1995; 72: 390. http://dx.doi.org/10.1136/hrt.73.4.390

[8] Singla V, Patra S, Patil S, et al. Accura balloon rupture during percutaneous trans-septal mitral commissurotomy: a rare and potentially fatal complication. Br Med J Case Rep. Published online May-2013. 